\title{
Spatial patterns of precipitation anomalies in eastern China during centennial cold and warm periods of the past 2000 years
}

\author{
Zhixin Hao, Jingyun Zheng, Xuezhen Zhang, Haolong Liu, Mingqi Li and Quansheng Ge* \\ Institute of Geographic Sciences and Natural Resources Research, Chinese Academy of Sciences, Beijing, China
}

\begin{abstract}
The spatial patterns of precipitation anomalies in eastern China during both warm and cold periods over the past 2000 years were studied. Four warm periods (AD 650-750, AD 1000-1100, AD 1190-1290, and AD 1900-2000) and five cold periods (AD 440-540, AD 780-920, AD 1390-1460, AD 1600-1700, and AD 1800-1900) were selected on a centennial timescale, referring to the synthesized temperature changes over China and Northern Hemisphere. The regional differences in precipitation were analysed and compared using a data set consisting of the grades in severity of floods and droughts as derived from Chinese historical documents. The results showed that there has been no fixed spatial pattern of precipitation anomalies during either cold or warm periods in eastern China over the past 2000 years. For the most of warm periods, there existed coherence of spatial pattern with dry condition only occurred over north of the Yangtze River, and the consistent spatial patterns were found between the periods 650-750 and 1190-1290, 650-750, and 1000-1100. For the cold periods, the precipitation showed various spatial patterns, and similarities were only presented in the two periods of 1600-1700 and 1800-1900 featured by meridional distribution. Comparing the spatial patterns between cold and warm periods, inverse pattern of 440-540 and 1900-2000 over the most study area can be detected, but similar pattern was also found between the periods 1800-1900 and 1900-2000, and 1600-1700 and 1900-2000. Our results implicated that the relationship between temperature and spatial pattern of precipitation anomaly has high complexity, which would be of significance to understanding the spatial pattern of precipitation in the future climate change study.
\end{abstract}

KEY WORDS centennial cold/warm periods; historical records; precipitation anomalies; spatial patterns; eastern China

Received 15 June 2014; Revised 13 March 2015; Accepted 11 April 2015

\section{Introduction}

Descriptions of the spatial patterns of climatic change and climatic variability on a regional scale over the last 2000 years are important in helping to understand past climate variability, in detecting the mechanisms of climate change, and in providing historical analogues to the current warming of the Earth's surface (PAGES, 2009). During the past 100 years, global warming may have altered the Earth's hydrological cycles. Models and observations suggest that anthropogenic forcing may have significantly contributed to the observed increases in precipitation in the mid to high latitudes of the Northern Hemisphere and to the observed decreases in precipitation in the subtropics and tropics of the Northern Hemisphere (Trenberth et al., 2007; Karl et al., 2009; Trenberth, 2011; PAGES, 2012). In China, observational evidence from 1951 to 2009 has shown that, despite an increase in average temperature of $1.0^{\circ} \mathrm{C}$, there has been no significant trend in the mean

\footnotetext{
* Correspondence to: Dr Q. Ge, Institute of Geographic Sciences and Natural Resources Research, Chinese Academy of Sciences, No. 11A Datun Road, Chaoyang District, Beijing 100101, China. E-mail: geqs@igsnrr.ac.cn
}

precipitation over the whole country. However, a precipitation pattern of negative anomaly in the north of the country and positive anomaly in the south has dominated since the 1970s (Ding et al., 2008). Some previously published studies have found that, during the Medieval Climate Anomaly (MCA), prolonged and severe droughts affected many parts of the western United States and northern Mexico (PAGES, 2011). European proxy records also show major hydrological anomalies during this time, with drier conditions in southern Europe and wetter conditions in north-western Europe (Seager et al., 2007; Burgman et al., 2010). Equatorial east Africa has experienced alternating climatic conditions, with an exceptionally long-lived drought during the MCA and a wet episode during the Little Ice Age (LIA) (Verschuren et al., 2000; Diaz et al., 2011).

Since the early 1980s, several studies have suggested that the spatial patterns of precipitation anomalies in China may be linked to fluctuations in temperature. For example, Zheng (1983) found that the climate tended to be drier in western China and wetter in eastern China for colder decades during the period 1470-1970, with an inverse pattern seen in warmer decades. Wang et al. (1993) showed 


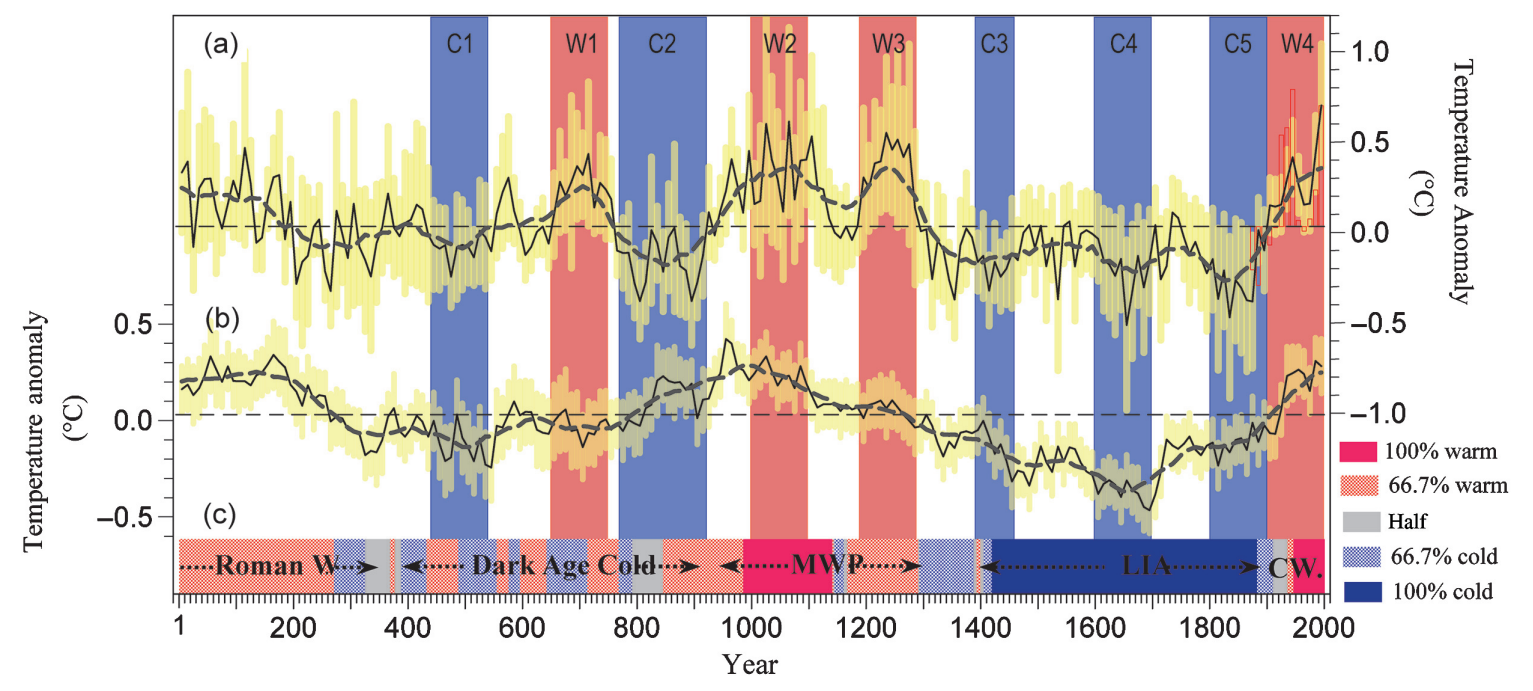

Figure 1. Temperature changes during the past 2000 years in (a) China (Ge et al., 2013a) and (b) the Northern Hemisphere (Ljungqvist, 2010). The solid line shows the decadal temperature anomaly (referenced to the mean value for AD 1851-1950) and the broken line shows the anomaly with 100-year smoothing. The shaded areas represent uncertainties at the $95 \%$ confidence level. The red and blue bars are the four warm and five cold periods selected for this study. (c) Percentage of six published temperature series in the Northern Hemisphere indicating cold and warm periods (Ge et al., 2013b); the main climatic stages are from Lamb (1977).

that wet conditions were prevalent over south of the Yangtze River during the MCA (950-1250), but that wet conditions dominated over the north of China during the LIA (1550-1850). Yang et al. (2014) studied the variations in drought conditions at the northern boundary of the Asian summer monsoon in China; they found that drought was consistent in the western and eastern parts of this belt, except during the coldest period, AD 1625-1644, when there was a pattern of wet conditions in the west and dry conditions in the east. Sporadic precipitation proxies from several different natural archives in local sites and several short-term time-slices also showed inconsistent patterns (Shao et al., 2006; Chu et al., 2009). Simulation results from the ECHAM4 - HOPE-G (ECHO-G) coupled ocean-atmosphere model indicated that more precipitation occurred in the warm periods and less precipitation in the cold periods; the phases (cold spells and warm peaks) of the variations in precipitation lagged behind those of temperature (Wang et al., 2011). However, there are still large uncertainties in the main spatial patterns of precipitation associated with decadal-centennial cold/warm periods over China and there is inconsistent knowledge of large-scale dry and wet spatial patterns for the typical warm and cold periods. More accurate analyses using high-resolution precipitation proxy data sets are required.

In the work reported here, we used a data set derived from Chinese historical documents of the grade of droughts and floods to establish the spatial patterns of changes in precipitation for centennial warm and cold periods over eastern China during the past 2000 years. We aimed to investigate whether any coherence existed in the spatial patterns of changes in precipitation for each warm period or cold period. The result may have implication for spatial patterns of precipitation anomaly in the future studies of climate change.

\section{Data and methods}

2.1. Temperature series used for selecting centennial warm/cold periods

A 2000-year temperature series (Ge et al., 2013a) was used to identify centennial warm/cold periods (Figure 1). This series was reconstructed from sub-regional proxy data for temperature across China with relatively high confidence levels. Each sub-regional proxy series for temperature was developed by envelope assessment (Ge et al., 2010) based on several proxies (such as historical documents, tree rings, ice cores, lake sediments, and stalagmites) from individual sites or small regions. The total number of proxies was 28 for the whole country and most of the proxies had a time resolution finer than 10 years. Compared with earlier temperature reconstructions for China (e.g. Yang et al., 2002; Wang et al., 2007) developed using synthesized temperature proxies from individual site, this reconstruction has a better spatial coverage because the proxies used for the synthesis are from more sites, with many new samples over the whole country.

This new reconstruction shows that the fluctuation of cold and warm periods over China is consistent with that in the Northern Hemisphere, as reconstructed by Mann et al. (2008; the errors-in-variables land reconstruction was included), Ljungqvist (2010), McShane and Wyner (2011) and Christiansen and Ljungqvist (2012). The temporal pattern of temperature change in China is consistent with that in the Northern Hemisphere as reconstructed by Ljungqvist (2010), except for an evident mismatch during AD 701-850. From Figure 1, we selected four warm periods including AD 650-750 (W1), AD 1000-1100(W2), AD 1190-1290 (W3) and AD 1900-2000 (W4), and five cold periods including AD 440-540 (C1), AD 780-920 (C2), AD 1390-1460 (C3), AD 1600-1700 (C4), and AD 1800-1900 (C5) as the intervals for the centennial 
Table 1. Criteria for calibrating the drought/flood grade and descriptions of drought/flood disasters recorded in historical documents (Zhang, 1996).

\begin{tabular}{lcl}
\hline Grade & Frequency distribution (\%) & Descriptions with meaning in historical documents \\
\hline 1 & 10 & $\begin{array}{l}\text { Continuous drought lasting 2 or more months in wet season (usually May to } \\
\text { September) or crossing two seasons with severe intensity and impact over a } \\
\text { broad area, such as 'villages for hundreds of miles were abandoned' } \\
\text { Drought lasting 2 months or more than 1 month in wet season with visible } \\
\text { impacts } \\
\text { Usual case (such as 'rain blended well in seasons') or nothing special to be } \\
\text { recorded, or harvest years }\end{array}$ \\
3 & 40 & $\begin{array}{l}\text { Flood lasts less than 2 months or heavy flood in wet season with evident impact } \\
\text { Continuous flood lasting 2 or more months, or extraordinary flood in wet season } \\
\text { with severe impacts, such as 'driving boats over land' }\end{array}$ \\
\hline 5
\end{tabular}

spatial patterns of precipitation anomalies. The period W1 matches the warm interval of the Dark Ages Cold and W2 and W3 approximately match the two warm peaks of the MCA. C1 and C2 are coincident with the cold valleys in the Dark Ages Cold and C3, C4, and C5 are the cold valleys in the LIA (Figure 1).

It is worth noting that the choice of the warm/cold events highly relies on the used different reconstruction series. For example, the cold and warm periods identified from the two tree-ring based reconstructions (Yang et al., 2012; Datsenko et al., 2014) in the northeast of Tibetan Plateau revealed a close connection of the climate variations with the solar activity events during the last millennium. But the regional cold and warm stages still have discrepancies with our selections. Thus, the reconstructions with large spatial coverage and more individual proxies involved should be selected.

\subsection{Data set for spatial patterns of precipitation anomalies on a centennial timescale}

The data set used for reconstructing the spatial patterns of precipitation anomalies on a centennial timescale is an annual index of the grade in severity of drought/flood derived from descriptions of drought and flood disasters (with direct impacts on agriculture and society) recorded in Chinese historical documents (Zhang, 1996). The grades were classified using the ideal frequency criteria of $10 \%$ (grade 1, severe drought), $20 \%$ (grade 2, drought), $40 \%$ (grade 3, normal), 20\% (grade 4, flood), and $10 \%$ (grade 5, heavy flood) for whole area and all time, which were calibrated with the intensity, duration, and area of the disaster, and its impact (Table 1). This data set covers 63 sites (Figure 2(a)) in eastern China (approximately east of $105^{\circ} \mathrm{E}$ and south of $40^{\circ} \mathrm{N}$ on the mainland) and extends to $137 \mathrm{BC}$ with a resolution of 1 year. Some of the index data for the grade of drought/flood before 1470 were unavailable (see Figure 2(b) for the percentage of available drought/flood grade data, excluding grade 3 ) as fewer historical documents survive from these earlier times (Zhang, 1996). In addition, the data for the grade of drought/flood were unevenly distributed spatially, i.e. there were few available data for grade of drought/flood in China before AD 760 and even fewer data in south of the Huaihe River (approximately $34^{\circ} \mathrm{N}$ ) before AD 300 (Zhang, 1996).
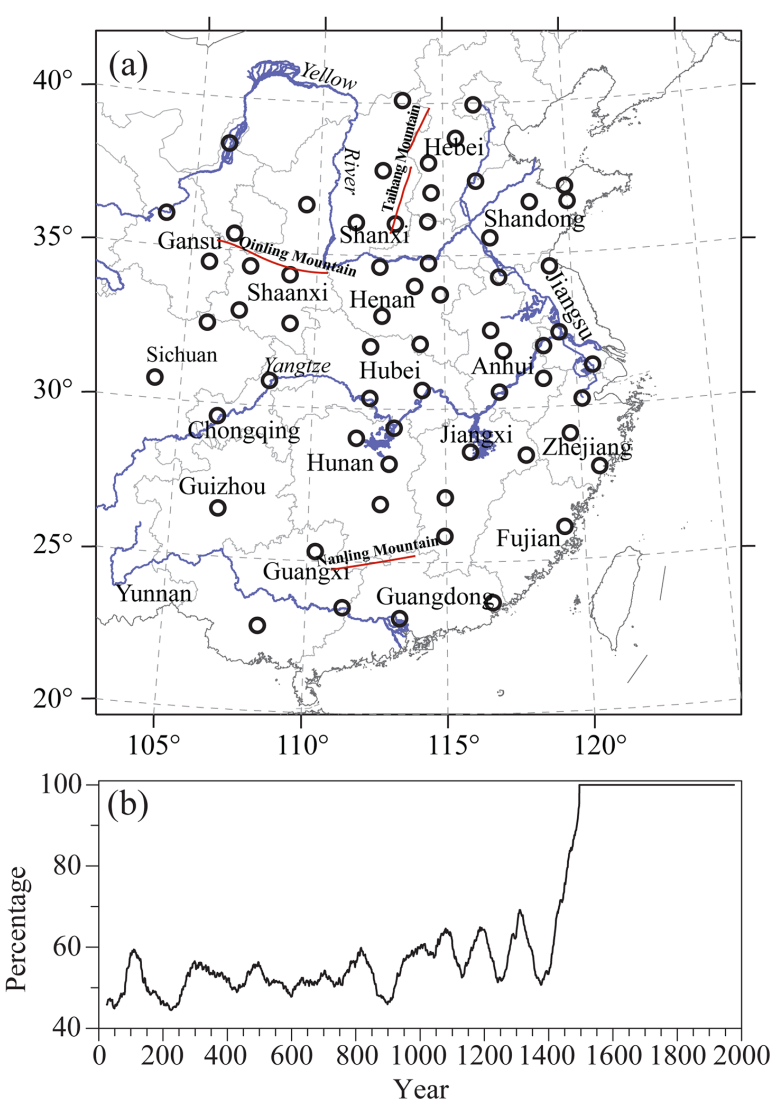

Figure 2. (a) Distribution of the sites used in the data set for the grade of drought/flood and the names of the provinces, rivers, and mountains referred in this study. (b) Percentage of data for the drought/flood grade that was available, excluding drought/flood grade 3 .

Compared with the data set of yearly dryness/wetness grades $(1=$ very wet, $2=$ wet, $3=$ normal, $4=$ dry, $5=$ very dry) for 120 stations in China from 1470 to 1979 (Academy of Meteorological Science of China Central Meteorological Administration, 1981), this data set covered a longer duration of time. This data set also covered more areas with a higher spatial resolution than the data set reconstructed by Zhang et al. (1997) for six regional series of grades for dry/wet conditions from AD 960 to 1992 from the Lower Yangtze Valley to the North China Plain. This dataset, thus, provides a valuable proxy to study the spatial 
patterns of changes in precipitation for centennial warm and cold periods over eastern China back to the past 2000 years. By using this data set, Zheng et al. $(2001,2006)$ studied the characteristics of changes in the bicentennial drought/flood spatial patterns from AD 101 to 1900 and reconstructed a 1500 year regional dry/wet index series for the North China Plain (approximately $34-40^{\circ} \mathrm{N}$ ), the Jiang-Huai area (approximately $31-34^{\circ} \mathrm{N}$ ) and the Jiang-Nan area (approximately $25-31^{\circ} \mathrm{N}$ ).

\subsection{Method for reconstructing spatial patterns of precipitation anomalies on a centennial timescale}

To avoid the effect of missing data on the estimation of precipitation anomalies in a certain period, we used the difference between drought and flood frequency (DDF) in our calculations. The DDF is deduced as follows:

For a $t$-year period (i.e. a warm period or a cold period) starting at year $s$, the ratio at which grade $k$ occurs at site $j$ in the given period will be:

$$
p_{j}^{k}=\frac{\sum_{i=s}^{s+t-1} F_{i j}^{k}}{\sum_{i=s}^{s+t-1} F_{i j}^{T}}
$$

where $k$ is the selected grade of drought/flood, i.e. $k=1$, $2,4,5$ where $1=$ severe drought, $2=$ drought, $4=$ flood, and $5=$ heavy flood, respectively, and $T$ represents all drought/flood grades (except for normal condition), $F_{i j}^{k}$ is the frequency of $k, F_{i j}^{T}$ is the frequency of $T$ (missing data are excluded).

The ratio at site $j$ at which grade $k$ appears within the reference period covers $M$ years (e.g. over all 2000 years, over one of the time periods such as AD 850-1850, or all warm and cold periods) will be:

$$
\bar{p}_{j}^{k}=\frac{\sum_{i=1}^{M} F_{i j}^{k}}{\sum_{i=1}^{M} F_{i j}^{T}}
$$

For any site, although the occurrence of missing data increases back in time, the missing probabilities for drought and flood records were random, i.e. when one period with a large number of documents, it had rich both drought and flood records, and vice versa. Therefore missing data should not have a significant effect on the value of $p_{j}^{k}$ on timescales longer than a decade. Thus the rate of $p_{j}^{k} / p_{j}^{k}$ indicates the deviation of the frequency of drought/flood at site $j$ when a grade $k$ drought/flood appears within a $t$-year time period from a reference period.

Finally, the index of DDF at site $j$ for a warm or cold period is defined as:

$$
\mathrm{DDF}_{j}=2 \cdot \frac{p_{j}^{5}}{\bar{p}_{j}^{5}}+\frac{p_{j}^{4}}{\bar{p}_{j}^{4}}-\frac{p_{j}^{2}}{\bar{p}_{j}^{2}}-2 \cdot \frac{p_{j}^{1}}{\bar{p}_{j}^{1}}
$$

From this definition, it is easy to see that the DDF value indicates the balance between the degree of deviation of the frequency of drought/flood within a specific time period from the frequency in a reference period. When $\mathrm{DDF}=0$, the degree of deviation of the frequency of drought in a specific time period is equivalent to the degree of deviation of the frequency of flood in a given reference period, which indicates that the dry/wet condition in that specific time period is equivalent to that in the reference period. When DDF $<0$, this means that the conditions in a specific period are dry relative to the reference period; when DDF $>0$, this means that the conditions in a specific period are wet relative to the reference period. The absolute value of DDF indicates the degree of deviation of the dry/wet conditions, i.e. a larger value indicates severe drought or flood. We can therefore use Equation (1) to illustrate the spatial patterns of precipitation anomalies for each of the specified warm and cold periods.

On the basis of definition of DDF, the deviation of DDF in the specific period from the reference period is caused by the change of drought and flood grade frequency distribution in the specific period comparing with that in the reference period. Therefore, the chi-squared test, which is used to test whether there is significant difference between the two distributions usually (Wei, 2007), is used here to evaluate the significance of the deviation of DDF between the specific period and the reference period.

\subsection{Verification}

To verify the results, the reference period was set as one of four periods: (1) the whole 2000 years (AD 1-2000); (2) all the selected warm and cold periods; (3) AD 850-1850, representing the natural millennium climatology covering the inter-centennial warm and cold periods (i.e. the MCA and LIA); and (4) AD 1500-2000, representing the time period in which all the annual data on grade of drought/flood were available (no missing data). Comparing the spatial patterns of precipitation based on the four reference periods (see Figure S1, Supporting Information), although the percentage of missing data was different in each reference period, the characteristics of the data in the same warm/cold stages were very similar. For example, Figure 3 shows the spatial patterns of precipitation anomalies during the period AD 780-920. All the four maps show consistent dry/wet conditions: dry in south-east and north-west, but wet in the central areas, although there are differences in the severity of dry or wet conditions between the four reference periods. Therefore the different reference periods and missing data for the grade of drought/flood may not affect the results of the spatial patterns; this shows that our method of analysis for the reconstruction of the spatial patterns is reasonable.

\section{Results}

The spatial patterns of precipitation anomalies on a centennial timescale for the five cold and four warm periods are plotted in Figure 4 using the mean value of all 

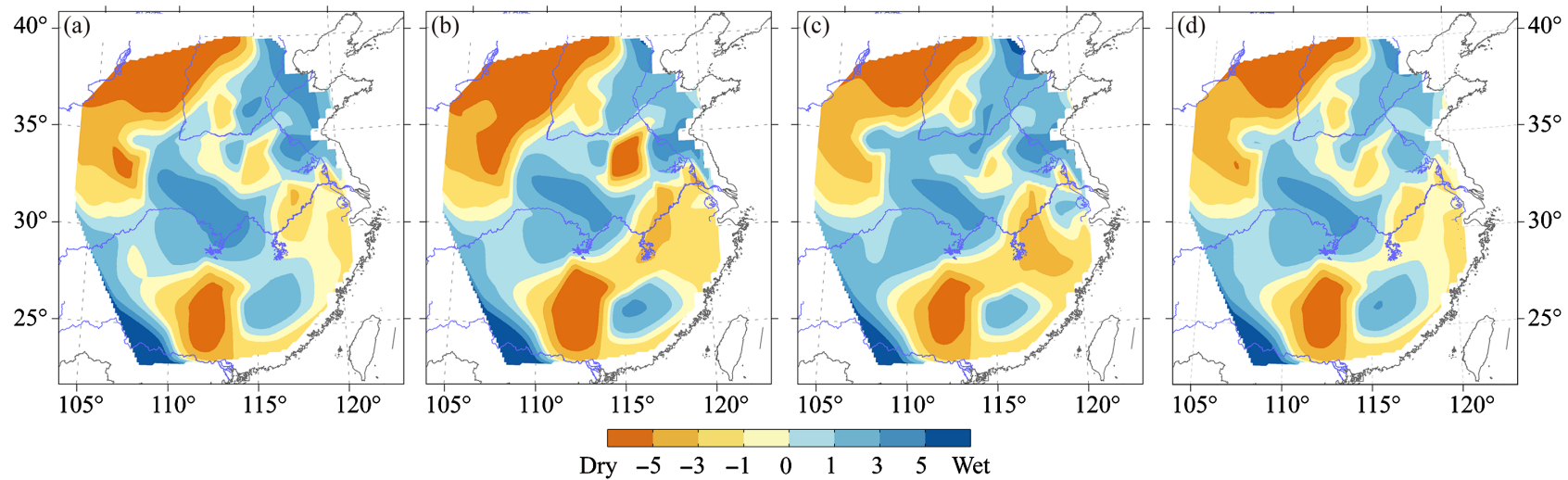

Figure 3. Spatial patterns of precipitation anomaly (DDF) during the period AD 780-920 based on different reference periods: (a) AD 850-1850; (b) AD 500-2000; (c) all selected warm and cold periods; and (d) all the past 2000 years.
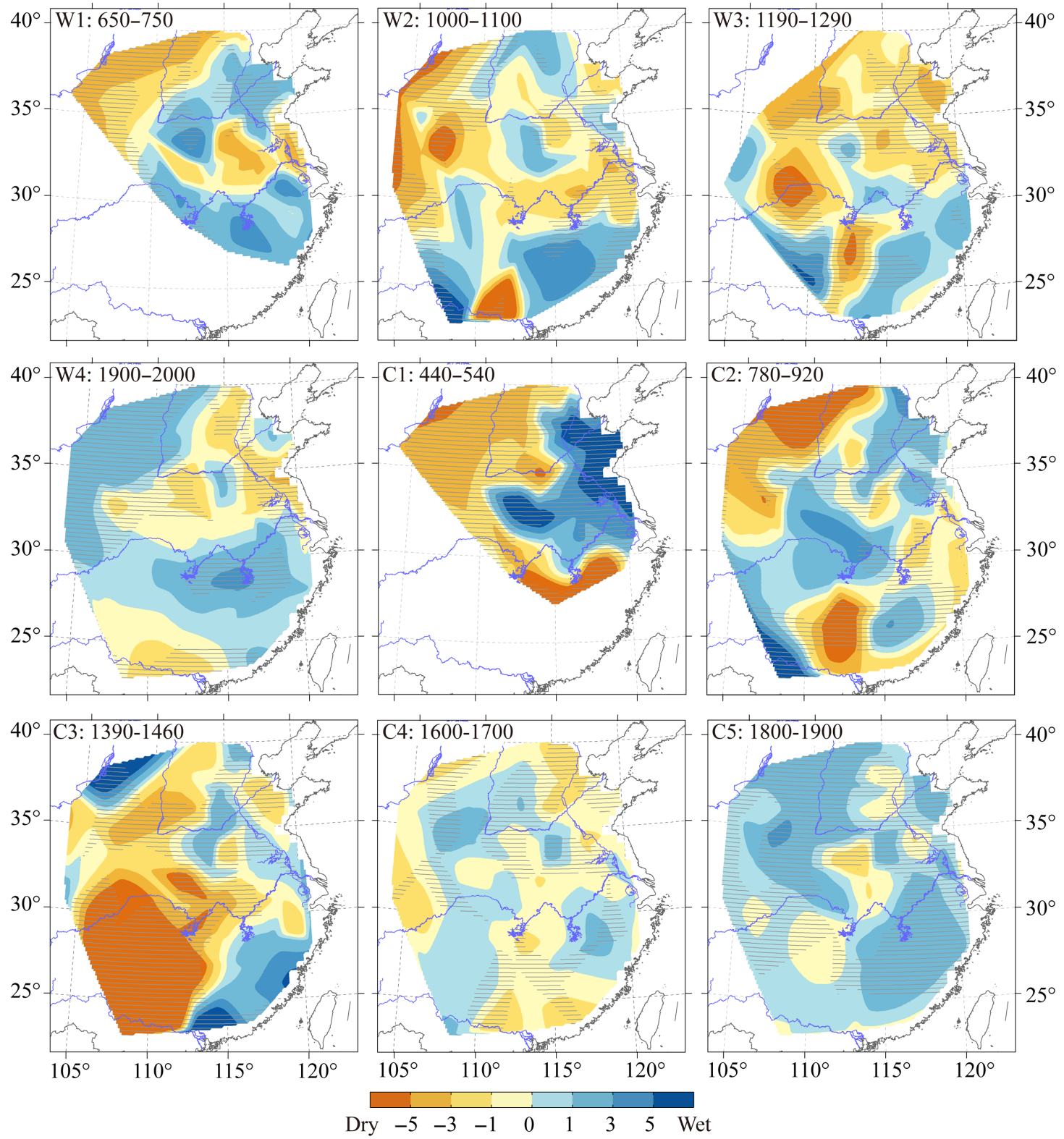

Figure 4. Spatial patterns of precipitation anomalies (DDFs, reference period the whole of the past 2000 years) during the four warm and five cold periods on a centennial timescale over eastern China. The shaded area passed $90 \%$ significance level by chi-square test. 
of the past 2000 years as the reference. In addition, in order to show the statistically significant different areas from the reference period, the chi-squared test at $90 \%$ significant level was conducted. During the first warm period (W1; AD 650-750), the eastern part of the Northwest and the valley of the Huaihe River were both under dry conditions, but the middle and lower reaches of the Yellow River valley and south of the Yangtze River valley were under wet conditions. During period W2 (AD $1000-1100$ ), east of $110^{\circ} \mathrm{E}$, the precipitation anomalies show a pattern of wet (south of the Yangtze River and in the eastern part of the south-west) - dry (most areas between 28 and $37^{\circ} \mathrm{N}$ ) - wet (Hebei Province and most of Shanxi Province) from south to north. However, there were dry conditions at west of $110^{\circ} \mathrm{E}$. This pattern looks similar to the leading pattern of precipitation anomaly for period of 1000-1100 (the warming interval of MWP) obtained from CESM1.0 and MPI Earth System Model simulations under full forcing including solar radiation, volcano, greenhouse gases, and land use (Man et al., 2012; Yan et al., 2014). For period W3 (AD 1190-1290) dry occurred in the north and wet in the south, approximately along the latitude $30^{\circ} \mathrm{N}$, except for the middle part of the Yangtze River valley and the Hanshui River valley, where there were dry conditions. In period W4 (AD 1900-2000), the spatial pattern shows zonal changes from south to north: dry in South China; wet in south of the Yangtze River (between 27 and $31^{\circ} \mathrm{N}$ ); dry in the Huaihe River valley and North China Plain; and wet conditions in the eastern part of the north-west. Although dry conditions were dominant in north of the Yangtze River valley in warm periods, the spatial patterns were inconsistent, particularly along the Yangtze River Valley, among the four warm periods.

The precipitation anomalies during the five cold periods also showed different spatial patterns. For period C1 (AD 440-540), the regions of the Yangtze River valley and the Huaihe River valley and the North China Plain were under wet conditions, but the upper and middle reaches of the Yellow River and south of Yangtze River were under dry conditions. For period C2 (AD 780-920), the climate showed a similar dry-wet-dry pattern to that seen in period W2 from south-east to north-west, in which the north-west and south-east were very dry, but the regions including the North China Plain and the middle reaches of the Yangtze River were wet. For period C3
(AD 1390-1460), the dry climatic anomaly was dominant. The spatial pattern showed dry in the west and wet bounded by east $115^{\circ} \mathrm{E}$; wet conditions mainly occurred in the south-east, the North China Plain (except the western part of Shandong Province and the southern part of Henan Province) and the northern part of Shaanxi. For period C4 (AD 1600-1700), the climate showed a meridional distribution, with dry in the east - wet in the middle (around $110^{\circ} \mathrm{E}$ longitude) - dry in the west; however, wet conditions were seen in south of the Yangtze River valley in the eastern region. For period C5 (AD 1800-1900), wet conditions were dominant, except in Guizhou, the Hanshui valley and part of north China. These five maps do not show consistent spatial patterns, although there are somewhat similarities between the periods C4 (AD 1600-1700) and C5 (AD 1800-1900). The similarities were featured by meridional distribution that is dry along $112^{\circ} \mathrm{E}$ and wet for the two sides.

To investigate any coherence in the spatial patterns of changes in precipitation among each warm period or each cold period, as well as the difference of spatial patterns between warm and cold period, the coefficients matrix of spatial patterns among warm and cold periods was shown in Table 2. The results showed that only $41 \%(16 / 39)$ coefficients passing the significant level at $\alpha=0.10$, in which half of them were positive (i.e. analogous pattern between two periods) and the other half were negative (i.e. inverse pattern for two periods).

For the warm periods, the highest positive coefficient with 0.427 was found between periods of 650-750 (W1) and 1190-1290 (W3), passing $\alpha=0.01$ significant level, which showed similar dry or wet conditions over the most study areas for both periods, except for the region of the mid-lower reaches of the Yellow River valley, where wet in W1 but dry in W3 (Figure 4). The second significant positive correlation was between periods of 650-750 (W1) and 1000-1100 (W2) with the coefficient of 0.328 , passing $\alpha=0.05$ significant level. The coefficients between the 1900-2000 and other three warm periods before the 20th century did not pass the $\alpha=0.1$ significant level i.e., no obvious analogous pattern exist between the 20th century and historical warm periods.

On the other hand, for the five cold periods, there was only one positive coefficient passing significant level at $\alpha=0.01$, which was between periods of $1600-1700$ and

Table 2. Matrix of coefficients for all warm and cold periods.

\begin{tabular}{|c|c|c|c|c|c|c|c|c|c|}
\hline \multirow[t]{2}{*}{ Periods } & & \multicolumn{4}{|c|}{ Warm } & \multicolumn{4}{|c|}{ Cold } \\
\hline & & $650-750$ & $1000-1100$ & $1190-1290$ & $1900-2000$ & $440-540$ & $780-920$ & $1390-1460$ & $1600-1700$ \\
\hline \multirow[t]{3}{*}{ Warm } & $1000-1100$ & 0.328 & & & & & & & \\
\hline & $1190-1290$ & $0.427 * * *$ & 0.127 & & & & & & \\
\hline & 1900-2000 & -0.216 & -0.103 & -0.188 & & & & & \\
\hline \multirow[t]{5}{*}{ Cold } & $440-540$ & 0.112 & -0.145 & -0.169 & $-0.520 * * *$ & & & & \\
\hline & 780-920 & $0.442 * * *$ & $0.440 * * *$ & 0.109 & $-0.267 * *$ & 0.158 & & & \\
\hline & $1390-1460$ & 0.007 & 0.098 & $0.343 * *$ & -0.100 & -0.042 & -0.161 & & \\
\hline & $1600-1700$ & -0.096 & 0.199 & -0.073 & $0.277 * *$ & $-0.360 * *$ & 0.078 & $-0.234 *$ & \\
\hline & $1800-1900$ & $-0.341 * *$ & -0.144 & $-0.226^{*}$ & $0.469 * * *$ & $-0.453 * * *$ & $-0.243 *$ & 0.015 & 0.419 *** \\
\hline
\end{tabular}

\footnotetext{
$*$, **, and $* * *$ indicate passing $\alpha=0.1, \alpha=0.05$, and $\alpha=0.01$ significant level, respectively.
} 

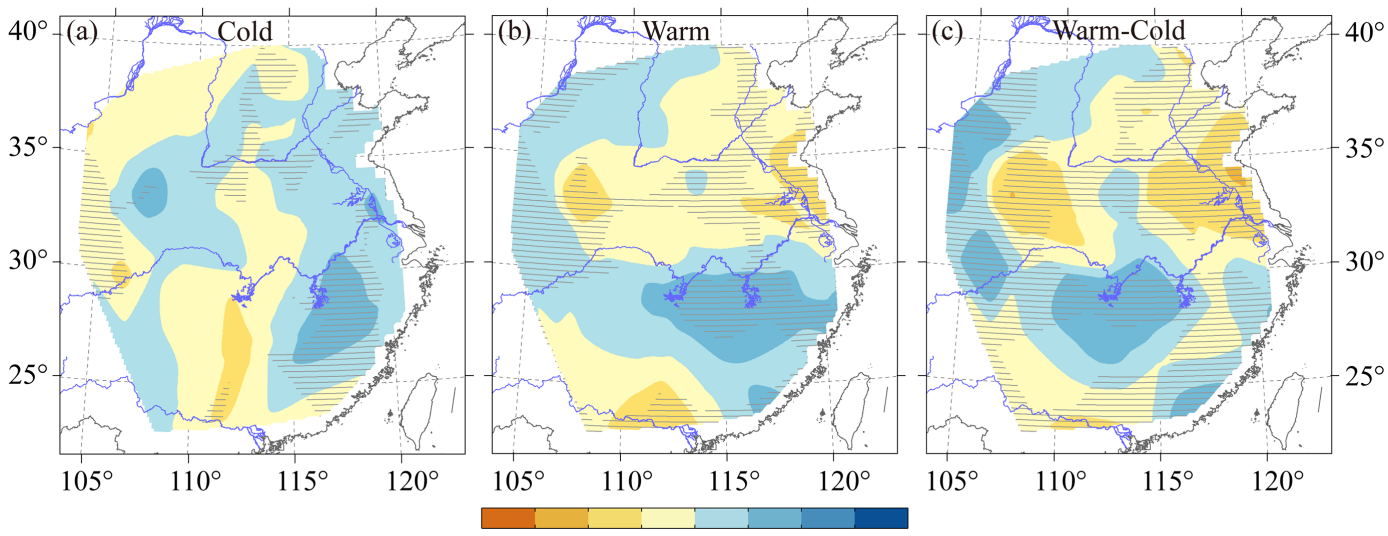

Dry $\begin{array}{llllllll}-5 & -3 & -1 & 0 & 1 & 3 & 5 & \text { Wet }\end{array}$

Figure 5. DDF ensemble mean of the four warm and five cold periods and the difference between them. (a) Five cold periods. (b) Four warm periods. (c) Difference between warm and cold periods (warm minus cold). The shaded area passed $90 \%$ significance level by chi-square test.

1800-1900. However, the negative significant coefficients were found between periods of 440-540 and 1800-1900, 440-540 and 1600-1700, passing the significant level at $\alpha=0.01$ and $\alpha=0.05$, respectively, as well as 780-920 and $1800-1900,1390-1460$ and $1600-1700$ with the significant level at $\alpha=0.10$.

For the correlations of the DDF spatial patterns between warm and cold periods, the negative coefficients were found between periods of 440-540 and 1900-2000 with highest value of -0.52 at a significance level of $\alpha=0.01$, which showed an inverse pattern over the most study area (W4 and C1 in Figure 4). Except in the southwest region, the spatial pattern of 1900-2000 (W4 in Figure 4) is the opposite of that of 780-920 approximately (C2 in Figure 4), with the coefficient of -0.27 (at $\alpha=0.05$ significance level). In addition, the significant positive coefficients were found between periods of 1800-1900 and 1900-2000 with wet in northwest and southeast for both, as well as 1600-1700 and 1900-2000 with dry in the most of north China and wet in its surrounding regions.

The above results suggested that there have been no fixed spatial patterns of precipitation anomalies during either cold or warm periods in eastern China over the past 2000 years, which implicated that the association between temperature variation and spatial pattern of precipitation change might be diversified combination.

\section{Discussion and conclusion}

As reported in previous studies, the climate was drier (wetter) in western China and wetter (drier) in eastern China for cold (warm) decades during 1470-1970 (Zheng, 1983); wet conditions were prevalent over south of the Yangtze River for the warm period 950-1250, and dominated in the north of China for cold period 1550-1850 (Wang et al., 1993). Their results presented the spatial pattern of precipitation anomaly during cold and warm periods, indicating the long-term climatic mean status. For the purpose of comparing with their results, the ensemble means of the DDF in the five cold periods and the four warm periods and their differences are illustrated in Figure 5. It was found that the spatial patterns between ensemble means of the DDF for cold and warm periods were quite different. For all five cold periods, the ensemble means of DDF showed a meridional distribution from east to west (Figure 5(a)). Wet condition was presented in east of $115^{\circ} \mathrm{E}$ and the most of the area between 110 and $105^{\circ} \mathrm{E}$, whereas the most of the area between 115 and $110^{\circ} \mathrm{E}$, as well as the northwest, was under dry conditions. This spatial pattern was somehow similar to the features of dry in the west and wet in the east during cold decades reported by Zheng (1983). In contrast with the spatial pattern seen in the cold periods, the warm periods showed a zonal distribution of dry-wet-dry (Figure $5(\mathrm{~b})$ ) bounded by latitude 25 and $30^{\circ} \mathrm{N}$. This pattern is somewhat in common with the pattern of wet in south of the Yangtze River during 950-1250 reported by Wang et al. (1993).

Moreover, the differences in the DDF ensemble mean between the warm and cold periods (Figure 5(c)), indicating the climatology of precipitation anomalies in eastern China, showed a complex pattern, in which, the dry centre located at the north of lower reaches of the Yangtze River and Qinling Mountain, whereas the wet centre located at the south of middle reaches of the Yangtze River. This spatial pattern was approximately similar to that of the observed precipitation change in 1956-2002, with the evident declining trend in annual precipitation over the Yellow River and ascending trend in south of Yangtze River (Ding et al., 2007), which was associated with the decreasing Asian summer monsoon (Ding et al., 2008). This result implicated that the probability of dry in north of the Yangtze River and wet in south of the Yangtze River in warm periods is higher than that in cold periods, although the association between temperature variation and spatial pattern of precipitation change varied case by case.

On the basis of analyses and comparisons reported in this paper, the following conclusions about the spatial patterns of precipitation anomalies for centennial warm and cold periods during the last 2000 years in eastern China are suggested. Although dry conditions were dominant in 
north of the Yangtze River valley, the spatial patterns were inconsistent among the four warm periods. They did not show consistent spatial patterns of precipitation anomalies among the five cold periods, although there were somewhat similarities between cold periods of 1600-1700 and 1800-1900, which both were featured by meridional distribution with dry along $112^{\circ} \mathrm{E}$ and wet for the two sides. Although the inverse patterns over most of the study area were found between cold period of 440-540 and warm period of 1900-2000, also between cold period of 780-920 and warm period of 1900-2000; the coherence was also found in cold (1800-1900) and warm (1900-2000) periods with wet in northwest and southeast. These results suggested that there has been no fixed spatial pattern of precipitation anomalies during either cold or warm periods in eastern China over the past 2000 years, which implicated that the association between temperature variation and spatial pattern of precipitation change should be varied case by case. Furthermore, our research showed that the relationship between temperature and spatial pattern of precipitation might be very complex, and could be of significance for understanding the uncertainty and diversification of spatial pattern for precipitation anomaly in the future climate change.

\section{Acknowledgements}

The authors would like to thank the anonymous referees' constructive comments, which help us to deeply understanding the complexity of relationship between temperature and precipitation. This research was supported by grants to Institute of Geographic Sciences and Natural Resources Research from the Chinese Academy of Sciences (XDA05080102; 2014RC101). All contributing authors declare no conflicts of interest.

\section{Supporting Information}

The following supporting information is available as part of the online article:

Figure S1. The spatial patterns of precipitation anomalies during the four warm periods (upper) and five cold periods (bottom) at different referenced periods including all selected periods, 500-2000 years, 850-1850 years and whole past 2000-years.

\section{References}

Academy of Meteorological Science of China Central Meteorological Administration. 1981. Yearly Charts of Dryness/Wetness in China for the Last 500 years. Cartographic Publishing House: Beijing.

Burgman R, Seager R, Clement A, Herweijer C. 2010. Role of tropical Pacific SSTs in global medieval hydroclimate: a modeling study. Geophys. Res. Lett. 37: L06705, doi: 10.1029/2009GL042239.

Christiansen B, Ljungqvist F. 2012. The extra-tropical Northern Hemisphere temperature in the last two millennia: reconstructions of low-frequency variability. Clim. Past 8: 765-786.

Chu GQ, Sun Q, Wang X, Li D, Rioual P, Qiang L, Han J, Liu J. 2009. A 1600 year multiproxy record of paleoclimatic change from varved sediments in Lake Xiaolongwan, northeastern China. J. Geophys. Res. 114: D22108, doi: 10.1029/2009JD012077.
Datsenko NM, Ivashchenko NN, Qin C, Liu J, Sonechkin DM, Yang B. 2014. A comparison between Medieval and current climate warming using the Przewalskii's Juniper tree-ring data. Russ. Meteorol. Hydrol. 39: $17-21$

Diaz HF, Trigo R, Hughes MK. 2011. Spatial and temporal characteristics of climate in medieval times revisited. Bull. Am. Meteorol. Soc. 92: $1487-1500$.

Ding YH, Ren GY, Zhao ZC, Xu Y, Luo Y, Li QP, Zhang J. 2007. Detection, causes and projection of climate change over China: an overview of recent progress. Adv. Atmos. Sci. 24: 954-971.

Ding YH, Wang XY, Sun Y. 2008. Inter-decadal variation of the summer precipitation in East China and its association with decreasing Asian summer monsoon. Part I: observed evidences. Int. J. Climatol. 28: $1139-1161$.

Ge QS, Zheng JY, Hao ZX, Shao XM, Luterbacher J. 2010. Temperature variation through 2000 years in China: an uncertainty analysis of reconstruction and regional difference. Geophys. Res. Lett. 37: L03703, doi: 10.1029/2009GL041281.

Ge QS, Hao ZX, Zheng JY, Shao XM. 2013a. Temperature changes over the past $2000 \mathrm{yr}$ in China and comparison with the Northern Hemisphere. Clim. Past 9: 1153-1160.

Ge QS, Liu J, Fang XQ, Yang B, Hao ZX, Shao XM, Zheng JY. 2013b. General characteristics of temperature change and centennial warm periods during the past 2000 years. Acta Geogr. Sin. 68: 579-592 (in Chinese).

Karl TR, Melillo JM, Peterson TC. 2009. Global Climate Change Impacts in the United States. Cambridge University Press: Cambridge, UK.

Lamb HH. 1977. Climate: Present, Past and Future, Vol. 2: Climatic History and the Future. Methuen: London.

Ljungqvist FC. 2010. A new reconstruction of temperature variability in the extra-tropical Northern Hemisphere during the last two millennia. Geogr. Ann.: Ser. A 92: 339-351.

Man WM, Zhou TJ, Jungclaus JH. 2012. Simulation of the East Asian Summer Monsoon during the last millennium with the MPI earth system model. J. Clim. 25: 7852-7866.

Mann ME, Zhang Z, Hughes MK, Bradley RS, Miller SK, Rutherford S, Ni FB. 2008. Proxy-based reconstructions of hemispheric and global surface temperature variations over the past two millennia. Proc. Natl. Acad. Sci. USA 105: 13252-13257.

McShane BB, Wyner AJ. 2011. A statistical analysis of multiple temperature proxies: are reconstructions of surface temperatures over the last 1000 years reliable. Ann. Appl. Stat. 5: 5-44.

PAGES. 2009. Science Plan and Implementation Strategy (IGBP Report No. 57). IGBP Secretariat: Stockholm.

PAGES. 2011. Medieval Climate Anomaly. PAGES International Project Office: Bern.

PAGES. 2012. Paired Perspectives on Global Change. PAGES International Project Office: Bern, Switzerland.

Seager R, Graham N, Herweijer C, Gordon A, Kushnir Y, Cook E. 2007. Blueprints for Medieval hydroclimate. Quat. Sci. Rev. 26: 2332-2336.

Shao XM, Liang EY, Huang L, Wang LL. 2006. A reconstructed precipitation series over the past millennium in the northeastern Qaidam Basin. Adv. Clim. Change Res. 2: 122-126 (in Chinese).

Trenberth KE. 2011. Changes in precipitation with climate change. Clim. Res. 47: 123-138, doi: 10.3354/cr00953.

Trenberth KE, Jones PD, Ambenje P, Bojariu R, Easterling D, Tank AK, Parker D, Rahimzadeh F, Renwick JA, Rusticucci M, Soden B Zhai P. 2007. Observations: surface and atmospheric climate change. In Climate Change 2007: The Physical Science Basis. Cambridge University Press: Cambridge, UK and New York, NY, 254-265.

Verschuren D, Laird KR, Cumming BF. 2000. Rainfall and drought in equatorial east Africa during the past 1,100 years. Nature 403: 410-414.

Wang SW, Zhao ZC, Chen ZH. 1993. Drought/flood type in China for 1950-1991. In Drought/Flood Disasters in Changjiang and Huanghe River Region and Its Impacts on the Economy. China Meteorological Press: Beijing, 55-66 (in Chinese).

Wang SW, Wen XY, Luo Y, Dong WJ, Zhao ZC, Yang B. 2007 Reconstruction of temperature series of China for the last 1000 years. Chin. Sci. Bull. 52: 3272-3280.

Wang HL, Liu J, Wang ZY, Wang SM, Kuang XY. 2011. Simulated analysis of summer climate on centennial time scale in eastern China during the last millennium. Chin. Sci. Bull. 56: 2229-2235, doi: 10.1007/s11434-011-4548-2.

Wei FY. 2007. Modern Climatic Statistical Diagnosis and Prediction Technology. Meteorological Press: Beijing (in Chinese). 
Yan M, Wang ZY, Liu J. 2014. Simulation of the characteristics and mechanisms of Chinese typical warm periods over the past 1500 years. Quat. Sci. 34: 1166-1175 (in Chinese).

Yang B, Braeuning A, Johnson KR. 2002. General characteristics of temperature variation in China during the last two millennia. Geophys. Res. Lett. 29: 381-384, doi: 10.1029/2001GL014485.

Yang B, Sonechkin DM, Datsenko NM, Ivashchenko NN, Liu JJ, Qin C. 2012. Eigen analysis of tree-ring records: part 3, taking heteroscedasticity and sampling effects into consideration. Theor. Appl. Climatol. 107: 519-530, doi: 10.1007/s00704-011-0498-5.

Yang B, Kang SY, Ljungqvist FC, He MH, Zhao Y, Qin C. 2014 Drought variability at the northern fringe of the Asian summer monsoon region over the past millennia. Clim. Dyn. 43: 845-859, doi: 10.1007/s00382-013-1962-y.
Zhang PY. 1996. Historical Climate Change of China. Shandong Science and Technology Press: Jinan, China, 307-338 (in Chinese).

Zhang DE, Liu CZ, Jiang JM. 1997. Reconstruction of six regional dry/wet series and their abrupt changes during the last 1000 year in east China. Quat. Sci. 17: 1-11 (in Chinese).

Zheng SZ. 1983. The patterns of dryness from cold and warm decades in historical times of China. Geogr. Res. 2: 32-40 (in Chinese).

Zheng JY, Zhang PY, Ge QS. 2001. Centennial changes of drought/flood spatial pattern in eastern China for the last 2000 years. Prog. Nat. Sci. 11: $280-287$.

Zheng JY, Wang WC, Ge QS, Man ZM, Zhang PY. 2006. Precipitation variability and extreme events in eastern China during the past 1500 years. Terr. Atmos. Ocean. Sci. 17: 579-592. 